Article

\title{
Is Forest Restoration in the Southwest China Karst Promoted Mainly by Climate Change or Human-Induced Factors?
}

\author{
Hongyan Cai ${ }^{1}$, Xiaohuan Yang ${ }^{1, *}$, Kejing Wang ${ }^{2}$ and Linlin Xiao ${ }^{1}$
}

1 State Key Laboratory of Resources and Environmental Information Systems, Institute of Geographic Sciences and Natural Resources Research, Chinese Academy of Sciences, 11A Datun Rd., Beijing 100101, China; E-Mails: caihy@igsnrr.ac.cn (H.C.); xiaoll.13b@igsnrr.ac.cn (L.X.)

2 East China Normal University, 3663 Zhongshan Rd., Shanghai 200062, China; E-Mail:wkj_3210@163.com

* Author to whom correspondence should be addressed; E-Mail: yangxh@igsnrr.ac.cn; Tel.: +86-10-6488-8608; Fax: +86-10-6488-9630.

External Editors: Yoshio Inoue and Prasad S. Thenkabail

Received: 1 July 2014; in revised form: 25 September 2014 / Accepted: 1 October 2014 / Published: 17 October 2014

\begin{abstract}
The Southwest China Karst, the largest continuous karst zone in the world, has suffered serious rock desertification due to the large population pressure in the area. Recent trend analyses have indicated general greening trends in this region. The region has experienced mild climate change, and yet significant land use changes, such as afforestation and reforestation. In addition, out-migration has occurred. Whether climate change or human-induced factors, i.e., ecological afforestation projects and out-migration have primarily promoted forest restoration in this region was investigated in this study, using Guizhou Province as the study area. Based on Moderate-Resolution Imaging Spectroradiometer (MODIS) Normalized Difference Vegetation Index (NDVI) data, we found general greening trends of the forest from 2000 to 2010 . About $89 \%$ of the forests have experienced an increase in the annual NDVI, and among which, about $41 \%$ is statistically significant. For the summer season, more than $65 \%$ of the forests have increases in summer NDVI, and about $16 \%$ of the increases are significant. The strongest greening trends mainly occurred in the karst areas. Meanwhile, annual average and summer average temperature in this region have increased and the precipitation in most of the region has decreased, although most of these changes were not statistically significant ( $p>0.1$ ). A site-based regression analysis using 19 climate stations with minimum land use
\end{abstract}


changes showed that a warming climate coupled with a decrease in precipitation explained some of the changes in the forest NDVI, but the results were not conclusive. The major changes were attributed to human-induced factors, especially in the karst areas. The implications of an ecological afforestation project and out-migration for forest restoration were also discussed, and the need for further investigations at the household level to better understand the out-migration-environment relationship was identified.

Keywords: forest greening; climate change; ecological afforestation project; out-migration; Southwest China karst

\section{Introduction}

Karst developed on soluble rock is an ecologically vulnerable environment that is subject to rocky desertification under high population pressure [1]. In a karst area, forest is generally the dominant land cover type. Monitoring forest change and identifying its causes are important because forest change influences climate variation by altering the carbon, water vapor, and energy exchange between the land surface and atmosphere [2]. More importantly, once forest is destroyed in a karst region, it is difficult to restore through natural succession, and rocky desertification usually follows due to the unique hydrological and geological conditions.

The satellite-based normalized difference vegetation index (NDVI) is widely used for monitoring and characterizing variations in vegetation cover [3,4], productivity [5], and phenology [6,7] from local to global scales. Based on a time series of NDVI observations and on model predictions, many studies have reported general greening trends (increasing trends in vegetation indices) in the northern mid-high latitudes $[8,9]$, which have mainly been attributed to the warming climate $[10,11]$. However, vegetation change and the controlling effect of climate have geographically and temporally varied [8,12]. For example, Zhou et al. [13] found a persistent increasing trend in growing-season NDVI in Eurasia, whereas the increasing trend in North America had a fragmented pattern in smaller areas. A study conducted in tropical mountain areas linked changes in NDVI to temperature variations in the same period and found that their relationship weakened over time or was negative [14], which was attributed to temperature-induced drought [10]. They also found that temperature and precipitation could not explain all of the changes in NDVI and other factors may therefore have partly contributed. Human-induced factors, e.g., abrupt changes in land use, also have an effect on vegetation changes. A recent dual-scale trend analysis attributed the increasing NDVI trend in European Russia to agricultural reform that encouraged the abandonment of agricultural land rather than to climate change [15]. According to a study in China, agricultural practices and land use changes, e.g., afforestation and reforestation, appear to make a greater contribution to the greening trend than temperature does [16]. Thus, at the regional scale, the relative role of climate change and human factors on vegetation dynamics is still not fully understood, especially in areas experiencing significant changes in land use [17].

Southwest China, which is characterized by a subtropical and tropical monsoon climate, holds the largest continuous karst zone in the world. Due to large population pressure coupled with the 
extremely ecologically vulnerable environment, this region has suffered serious rocky desertification. Over $20 \%$ of the karst area has degraded and is experiencing rocky desertification [18], which further increases the poverty of the population. Most of the population in this region struggle to meet their everyday needs. Over $40 \%$ of the rural population lives on less than US\$ 1 per day, which is lower than the international poverty line of US\$ 1.25 per day. To protect and improve the ecological environment in this region and in west China, the Chinese government implemented the "Returning Farmland to Forest" project in 1999, which involved 25 provinces in central and western China. By 2011, the area of forest has increased by about 28.94 million hectares through afforestation and reforestation. With the afforestation of sloping cultivated land and degraded farmland, large numbers of rural laborers have become surplus in terms of local needs and have moved away to work in large cities. This out-migration has changed the size and structure of the population in this region, which may, in turn, have affected the vegetation dynamics [19].

A recent trend analysis of vegetation greenness in China demonstrated general greening trends in this region [20]. Whether climate change or human-induced factors have promoted the forest restoration is uncertain; this was the focus of the present study. The results will provide useful information for ecological protection and redevelopment in this region. In addition, karst landform covers about one- tenth of earth surface [21], and many karst regions have suffered degradation due to increasing human activities coupled with highly vulnerable eco-geo-environment [22-24], thus this study may also provide highlights for other karst areas.

\section{Materials and Methods}

\subsection{Study Area}

The Southwest China Karst area mainly extends through Guizhou, Guangxi, and Yunnan Provinces (Figure 1), and among which Guizhou province has the largest area of karst as well as the most serious rock desertification [25]. Additionally, it is also the major focus of the "Returning Farmland to Forest" project, and ecological afforestation plots have been established in all counties in the region. Thus, this region was selected as the study area.

Guizhou Province is characterized by typical karst landforms, with a karst area of $11.3 \times 10^{4} \mathrm{~km}^{2}$, which is $64.2 \%$ of the total area of Guizhou Province [26]. Except for the southeastern area, Chishui in the western area, and Shanheng and Wangmo in the southern areas, karst covers most of the region (Figure 1). Located in the subtropical humid monsoon zone, this region has a mild climate, with an annual average temperature of $14-16^{\circ} \mathrm{C}$. The annual average precipitation is $1000-1300 \mathrm{~mm}$, which is mainly concentrated in the period from April to September. Benefiting from its climate, this region has abundant forest resources and a variety of forest types. The dominant forests in this region are subtropical evergreen needleleaf forest, evergreen broadleaf forest, mixed forest, and deciduous broadleaf forest. The major species include Cunninghamia Lanceolata, Pinus massoniana, Pinus Yunnanensis fr., Cupressus funebris, Populus sp., Betula sp., and Quercus sp. 
Figure 1. (a) The location of the Southwest China Karst and (b) the spatial distribution of forest in Guizhou Province according to land use data derived from Landsat TM/ETM+ and HJ-1 images in 2010. The legend shows the percent fractional cover of forest within 1-km pixels. Counties outlined with red are the areas without karst [26].

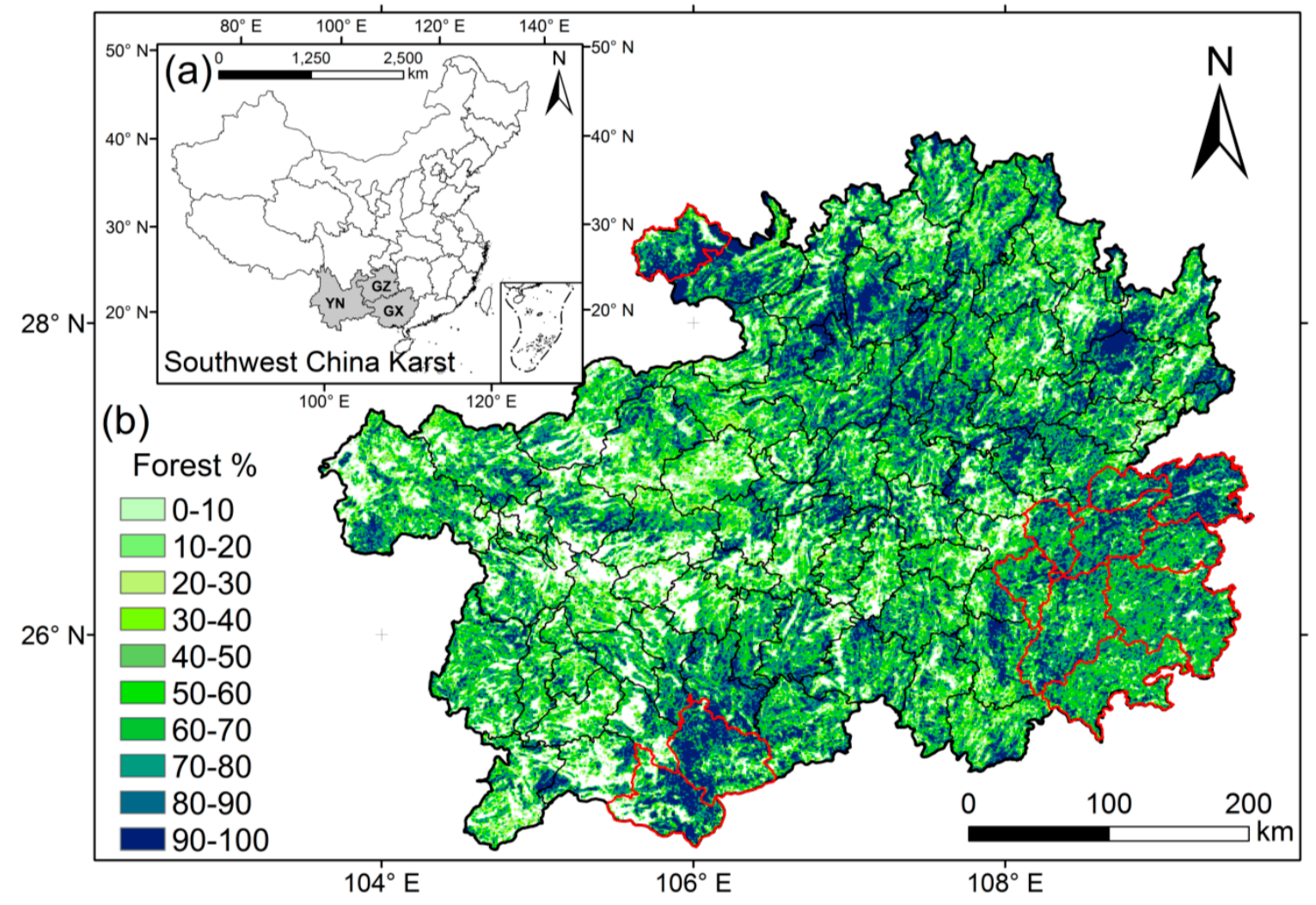

\subsection{Materials}

\subsubsection{Moderate-Resolution Imaging Spectroradiometer (MODIS) NDVI Time Series Data}

To investigate the inter-annual and seasonal trends of the forest, the MODIS monthly vegetation indices (VI) product (Collection 5, MOD13A3 at a spatial resolution of $1 \mathrm{~km}$ ) from 2000 to 2010 was collected from the Land Resources Distributed Active Archive Center (LPDAAC). Because they use an improved compositing approach as well as cloud and aerosol filtering, MODIS VI products are considered to be of high quality and suitable to capture vegetation dynamics [27]. In this study, monthly NDVI data were used to derive the summer and annual NDVI.

\subsubsection{Land Use Data}

Land use and its change data from 2000 to 2010 were collected from the National Resources and Environmental Scientific Data Center (RESDC) of the Chinese Academy of Sciences (CAS). These data were manually interpreted from Landsat TM/ETM+ and HJ-1 CCD images and then corrected and validated through fieldwork [28]. There were six classes in the land use data: cropland, forest, grassland, water bodies, built-up land, and unused land [29]. This study only considered forest conversion; thus, all conversions between forest and the other five classes were identified. The land 
use data used in this study were raster data produced by a $1 \times 1 \mathrm{~km}$ area proportion model [30]. The value in the grid represents the proportions of the area in the land-use class, or the changes.

\subsubsection{Climate Data}

Daily temperature and precipitation data from 19 climate stations in Guizhou Province were obtained from China Meteorological Administration. The quality of all daily records from these stations was checked, and after eliminating the invalid records, the average annual and summer temperature and precipitation were calculated.

\subsubsection{Out-Migrant Population (OMP)}

To determine whether there was a relationship between OMP and changes in the NDVI, the county-level OMP in 2000 and 2010 were calculated from the China census database produced by National Bureau of Statistics of China. According to the Sixth National Population Census of China, a migrant is defined as someone who has stayed away from the place where s/he has a household registration (hukou in Chinese) for more than half a year. Three types of immigration are included in the census data: (1) moving from another township/district in the same county; (2) moving from a township/district in another county in the same province; and (3) moving from another province. However, out-migration is not recorded in the database. In this study, we used the method proposed by Liu et al. [31] to estimate the amount of county out-migration. According to their method, the amount of out-migration was calculated as the difference between the total amount of immigration and net migration. Intra-county migration was not considered.

\subsection{Methods}

\subsubsection{NDVI Trend Analysis}

The annual average NDVI (annNDVI) and summer NDVI (sumNDVI) were used to characterize forest growth. The annNDVI represents the average status of forest growth in a year, whereas sumNDVI captures the forest growth over the peak season.

To determine the spatial patterns of the direction and rate of change in NDVI, trends in annNDVI and sumNDVI over time were estimated using ordinary least squares regression, and the trend slopes were calculated and mapped by pixel. Furthermore, significant trends at a $90 \%$ confidence level were also identified. For visualization purposes, trends in annNDVI and sumNDVI were expressed as a percentage relative to the value in 2000 , which was the starting point of the time series.

\subsubsection{Regression Analyses of NDVI and Climate Change}

To quantitatively measure the impacts of climate change on changes in forest NDVI, coefficients of determination $\left(\mathrm{R}^{2}\right)$ were estimated using linear regression equations, with NDVI as the dependent variable and temperature and precipitation as the independent variables [32-34]. This parameter provides a combined explanation of the independent variables. In this study, this parameter was used to identify the contribution of climate change to the variation in NDVI. The effect of climate change on 
vegetation variation may have a time lag [35,36], with a recent study in China identifying temperature and precipitation time lags in Guizhou Province that were mostly less than one month [20]. In this study, we only focused on annual and seasonal changes in NDVI and their relationship with climate; therefore, the time lag effect of climate was not considered. To reduce the influence of the misregistration of a climate station and MODIS NDVI pixels, NDVI values averaged for pixels within a window $(2 \times 2 \mathrm{~km})$ surrounding the climate station were compared with climate data. Additionally, land use changes in these windows were checked to avoid any effects on the relationships. This check was used to confirm that the climate stations were stable during the period of the study and that no apparent change in land use (changes lower than 5\% for 16 stations and around 10\% for 3 stations) occurred in their surrounding areas.

\subsubsection{Relationship between Out-Migration and Changes in the Forest NDVI}

The relationship between county OMP and changes in the NDVI was investigated using a spearman correlation analysis. The spearman coefficient measures the association between two variables (OMP and changes in the NDVI in this study) based on their rank orders [37], thereby avoiding any non-linearity that could undermine the detection of a monotonic relationship between OMP and changes in NDVI. The relationships of both the average amount and annual change in the OMP with changes in NDVI were determined to investigate the effects of scale and relative changes in OMP on changes in NDVI.

\section{Results and Discussion}

\subsection{Trends in annNDVI and sumNDVI}

Figure 2 shows the spatial distribution of the temporal trends in forest using the annNDVI and sumNDVI as parameters. From 2000 to 2010, greening (increasing) trends have occurred in most forest areas, and the sumNDVI and annNDVI have generally increased. More than $89 \%$ of the forests have experienced an increase in the annNDVI, and among which over $40 \%$ were statistically significant at a $90 \%$ confidence level. The significant increasing trends were extensively distributed throughout the region, and the strongest trends (more than $1.5 \%$ per year) occurred mainly in the western and northern regions, such as Weining, Panxian, Dafang, and Wuchuan-Yanhe-Dejiang. These trends are consistent with previous analyses in South China [20]. Compared with the NDVI trends from 1982 to 2003 [38,39], the forest greening trends during 2000-2010 observed in this study has spread westward and northward, and browning (decreasing) trends were only found in small patches in the south and east regions. The browning trends of NDVI in the former period shifted to greening trends in the latter period, especially for Weining in the southwest region. Greening trends in the sumNDVI also occurred over most of the region. About $65 \%$ of the forests have experienced an increase in the sumNDVI, and among which about $16 \%$ is statistically significant. However, the significant trends were less widely distributed; fewer significant increasing trends were observed westward and northward, and decreasing trends were mainly concentrated in the southeastern region and in patches in Chishui and Xishui in the northwestern region, which are generally not characterized 
by karst landforms. The NDVI trends analysis for the past decade indicated that forest restoration has generally occurred in the karst areas.

Figure 2. Spatial patterns of the temporal trends in annNDVI $(\mathbf{a}, \mathbf{b})$ and sumNDVI $(\mathbf{c}, \mathbf{d})$ from 2000 to 2010. Significant trends $(p<0.1)$ in annNDVI and sumNDVI are shown in left, respectively. Right represent the overall trends in annNDVI and sumNDVI. Outlined black areas are non-karst areas.
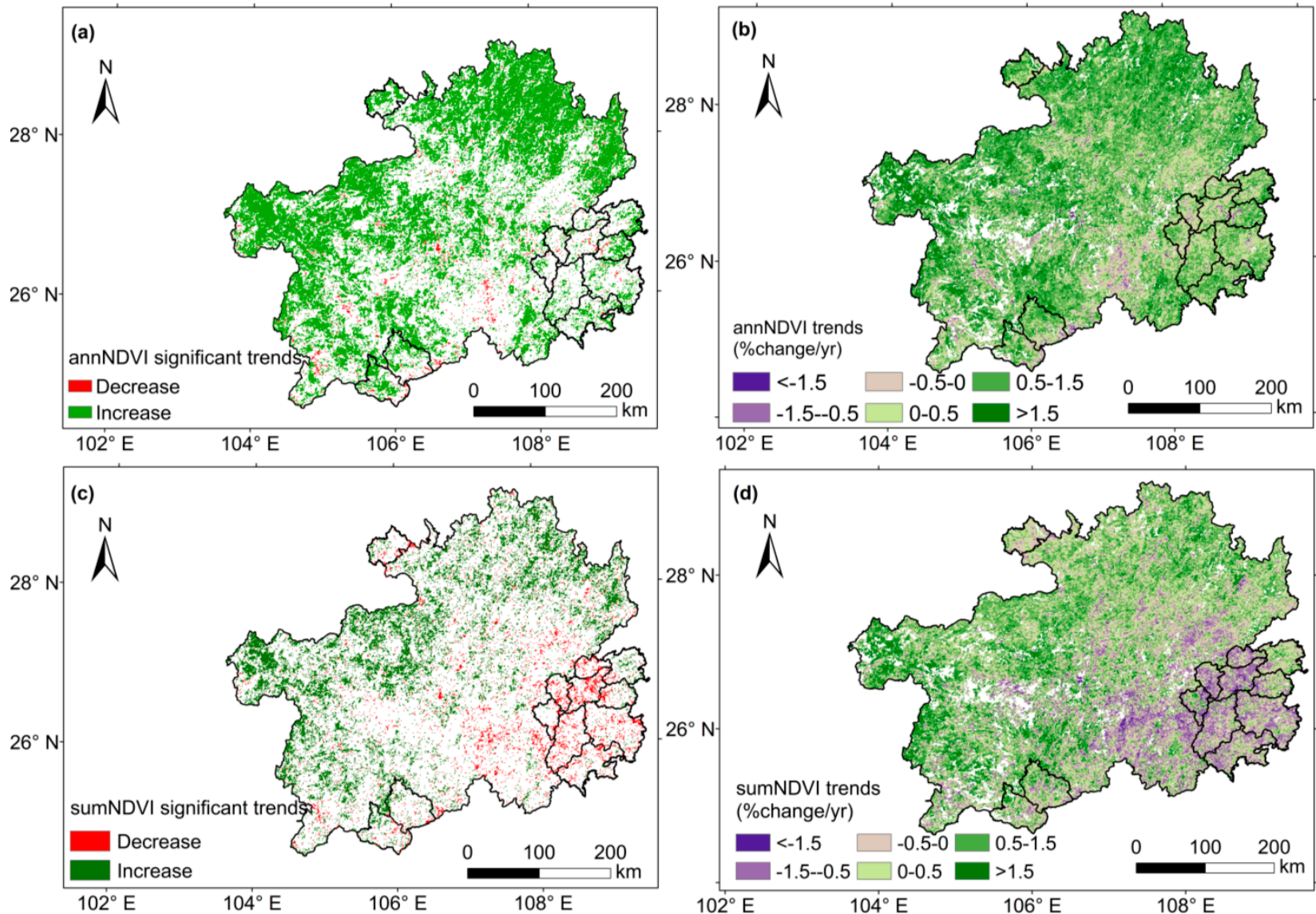

\subsection{Trends in Temperature and Precipitation over the Year and during Summer}

The regression of the annual average temperature against year from 2000 to 2010 (Figure 3a) shows warming trends at all climate stations, with the trend slopes increasing from $0.003{ }^{\circ} \mathrm{C} / \mathrm{yr}$ to $0.061{ }^{\circ} \mathrm{C} / \mathrm{yr}$. However, only one of 19 stations observed a significant increasing trend $(p<0.1)$. Similarly, summer temperatures in most stations (17 of 19) increased at a warming rate higher than the annual average and slopes of $0.021{ }^{\circ} \mathrm{C} / \mathrm{yr}$ to $0.083{ }^{\circ} \mathrm{C} / \mathrm{yr}$ (Figure $3 \mathrm{~b}$ ). The strongest warming trends occurred primarily in the northern and western regions, such as Weining, Tongzi, Zunyi, Meitan, and Tongren. During this period, annual and summer precipitation in most of the region decreased (Figure 3c,d). The strongest decreasing trends were mainly distributed in northern regions, whereas in the southern area, an increasing trend in precipitation was observed, especially in summer. 
Figure 3. (a-d) Trends of temperature and precipitation by year and summer from 2000 to 2010. The dots with black circles represent statistically significant trends. Outlined black crosshatched areas are non-karst areas.
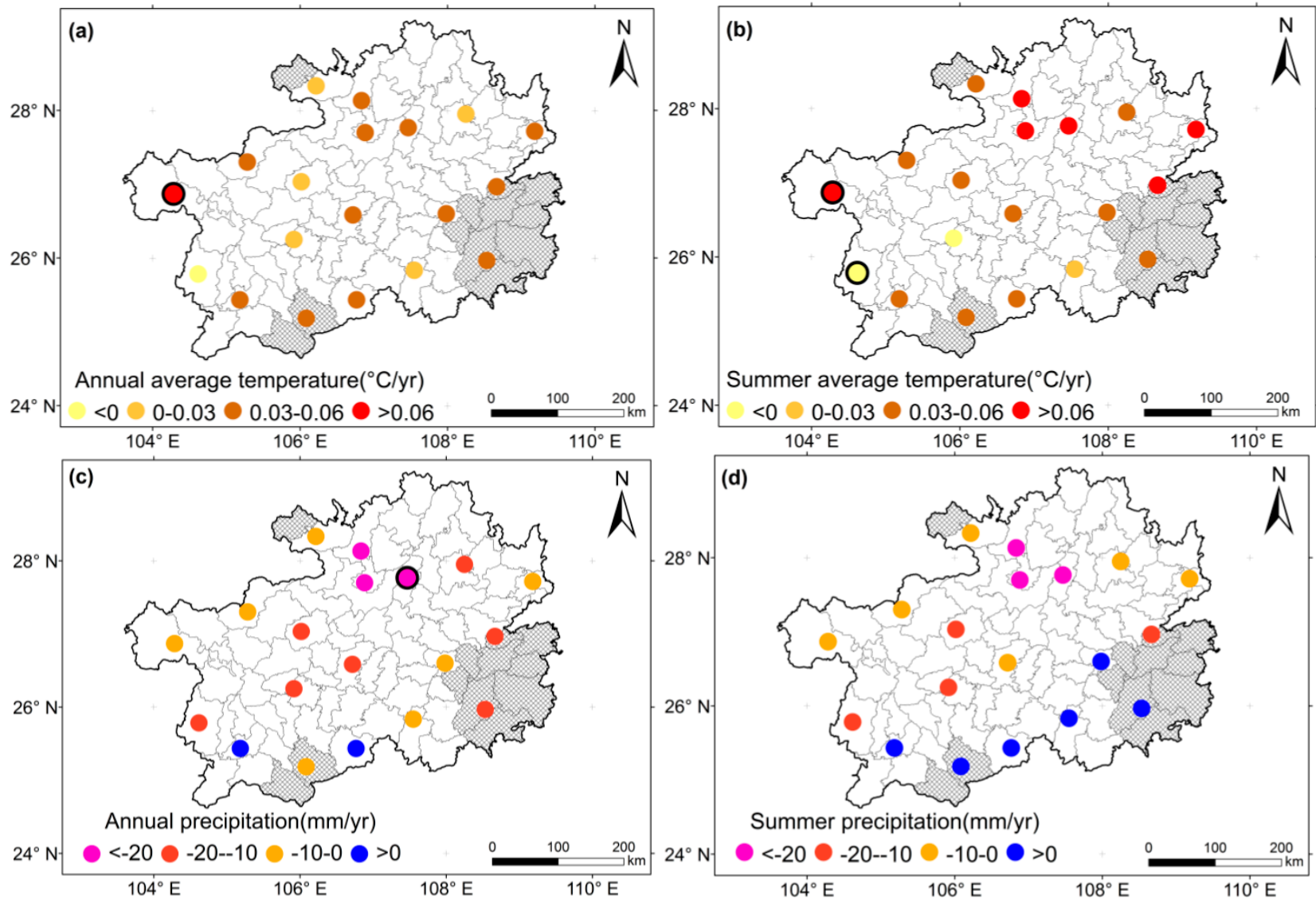

\subsection{The Relationship between NDVI and Climate Change}

Figure 4 shows the spatial distribution of $\mathrm{R}^{2}$ values from the regression equations, with temperature and precipitation as independent variables and the NDVI as the dependent variable. For most of the region (15 of 19 stations, $78.9 \%$ of the total), the annual average temperature and precipitation explained less than $40 \%$ of the annual changes in the NDVI, with $\mathrm{R}^{2}$ values ranging from 0.009 to 0.371. Significant relationships mainly occurred in the southeastern regions, such as Rongjiang, Kaili and Sanhui, and Qianxi in the western region, with $\mathrm{R}^{2}$ values ranging from 0.527 to 0.646 . This result indicates that, for most of the province, other factors may be primarily responsible for the greening trends in annNDVI, whereas in the southeastern regions, annual changes in the NDVI were largely explained $(53 \%-65 \%)$ by changes in temperature and precipitation. With regard to sumNDVI, temperature and precipitation in the summer explained $6 \%-43 \%$ of the changes, and the relationships were not statistically significant $(p>0.1)$. The summer climate had the greatest impact in the southeastern and northwestern regions. From Figure 4, it appears that changes in the forest cover in the karst area were less influenced by climate variation than that in the area without karst landforms. 
Figure 4. Coefficients of determination from the linear regression equations for (a) annNDVI and annual average temperature and precipitation and (b) sumNDVI and summer temperature and precipitation. The red dots with black circles indicate that the results are statistically significant $(p<0.1)$. Outlined black crosshatched areas are non-karst areas.
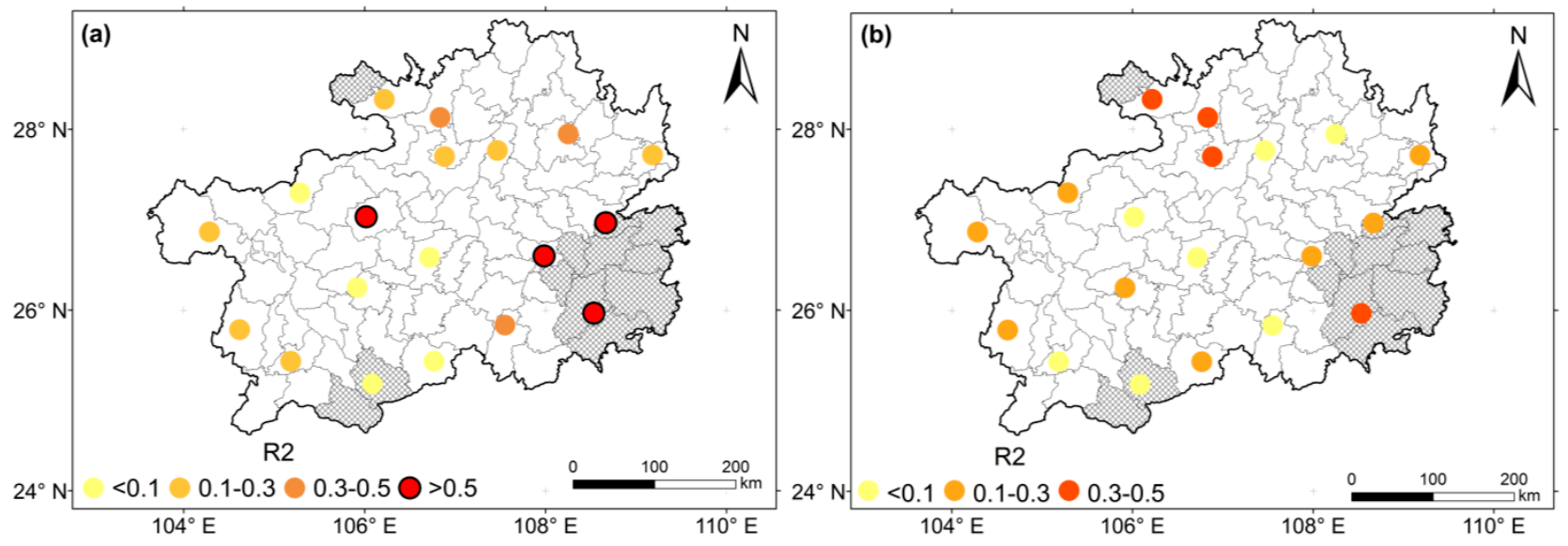

\subsection{The Effects of Afforestation and Out-Migration on Changes in the Forest NDVI}

\subsubsection{Changes in the Forest NDVI in relation to Ecological Afforestation}

To investigate the relationship between afforestation and changes in NDVI, major forest conversions were identified, especially in the areas experiencing significant changes in NDVI. Due to the ecological afforestation project, about $1851 \mathrm{~km}^{2}$ land has been converted to forest in Guizhou Province, with grassland (accounting for $73.8 \%$ of forest increase) and cropland $(25.7 \%$ of forest increase) being the major contributors. Although about $321 \mathrm{~km}^{2}$ of forests were transformed to other land uses, a net increase of $1583 \mathrm{~km}^{2}$ of forest cover occurred during the period from 2000 to 2010 .

In the area experiencing significant changes in annNDVI, there was a net increase in forest cover of $576 \mathrm{~km}^{2}$, and nearly $99 \%$ of this increase (about $574 \mathrm{~km}^{2}$ ) occurred in areas with a significant increasing trend in NDVI. The increase in forest cover was mainly attributed to conversions from grassland and cropland, which together accounted for $99 \%$ of the increase (Figure 5). Elsewhere, forest cover decreased by about $129 \mathrm{~km}^{2}$ during this period, with transformation to cropland accounting for $58.9 \%$ of the loss. This indicates that, although the ecological afforestation project has been fully implemented in this region, a large amount of existing forestland was still cultivated. There was a net increase in forest cover in the area experiencing significant changes in sumNDVI, with about $75 \%$ of the increase (about $268 \mathrm{~km}^{2}$ ) occurring in the area with significant increasing trends of summer NDVI. Most of the increase in forestland was due to conversion from grassland and cropland, which accounted for nearly $99 \%$ of the increase. 
Figure 5. Forest conversions in the area experiencing significant changes in the NDVI. (a) Conversion from other land uses to forest, (b) Conversion from forest to other land uses.
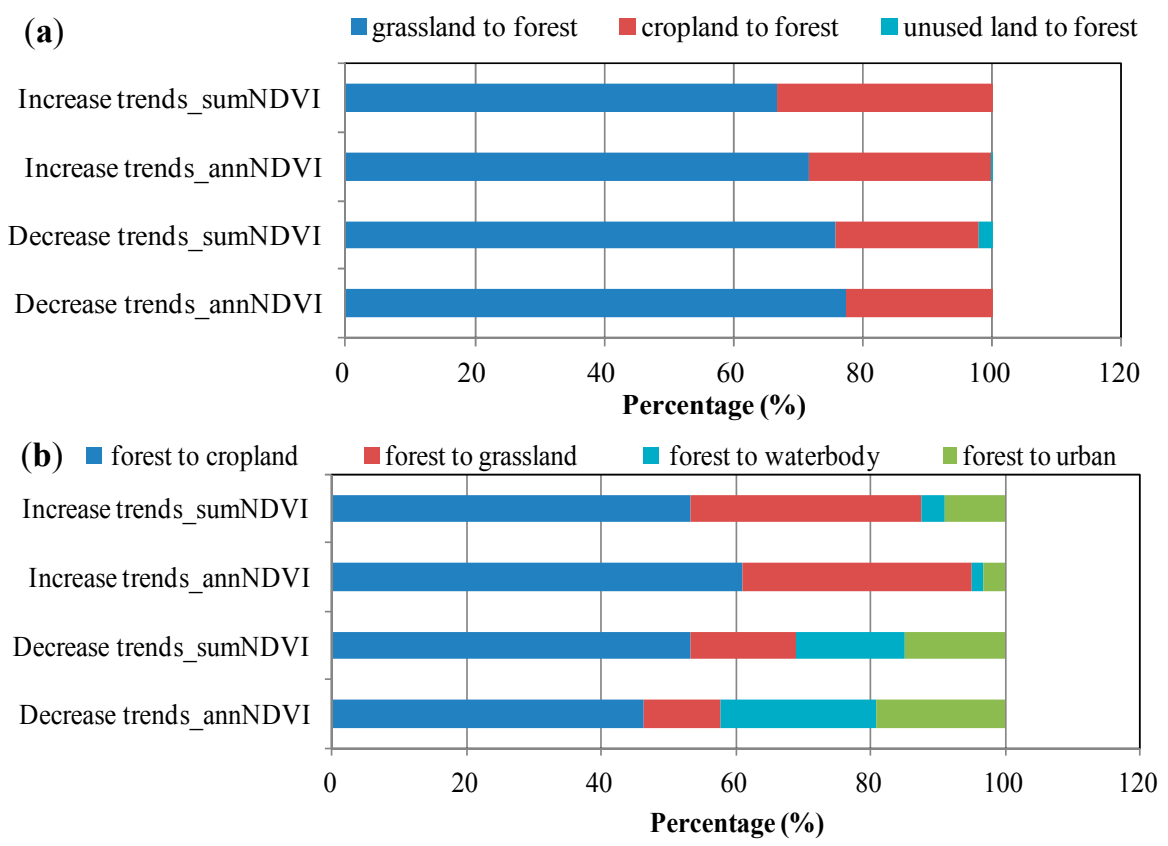

\subsubsection{The Relationship between OMP and Changes in the Forest NDVI}

According to the China census database, the total OMP in Guizhou Province increased from $31.6 \times 10^{4}$ in 2000 to $94.6 \times 10^{4}$ in 2010 . Figure 6 shows the spatial distribution of OMP at the county level. Except for Liupanshui, the OMP in all counties increased from 2000 to 2010. If a line is drawn from Tongren to Panxian, the OMP value in the counties above the line is much higher than that below the line. The temporal trends in annNDVI and sumNDVI in these two regions were also compared. The spatial patterns of the trends in annNDVI and sumNDVI were similar to those of the OMP. The average temporal slopes of annNDVI and sumNDVI in the areas above the line were both larger than those below the line, especially for sumNDVI (441\% higher).

We divided the OMP into five groups based on changes and amount of OMP, respectively, and the average trends for annNDVI and sumNDVI in each group were compared. Figure $7 \mathrm{a}$ shows the average trends for annNDVI and sumNDVI in each group according to the average OMP. The average annNDVI and sumNDVI trends for all groups were $>0$, except that for sumNDVI in group 1 , and the trends gradually increased from group 1 to 5 . This indicates that forest has turned green in most counties, and in the counties with higher OMP, the greening rate is larger. Furthermore, the standard deviation of sumNDVI in each group is much larger than that of annNDVI. This indicates that sumNDVI in each group is more distinct, probably because annNDVI disguised the seasonal change in the forest, whereas sumNDVI depicts this seasonal difference. According to the spearman correlation analysis, both annNDVI and sumNDVI were positively related to the average OMP $(p<0.001)$, with correlation coefficients of 0.474 and 0.495 , respectively. Compared with these relationships, the positive relationship between the NDVI trends and changes in OMP was not as strong (Figure 7b). The trends in annNDVI and sumNDVI increased from group 1 to 4 , whereas they fell slightly in group 5. The correlation coefficients were 0.381 for the annNDVI and 0.45 for the sumNDVI. 
Figure 6. Spatial distribution of the OMP in Guizhou Province from 2000 to 2010.

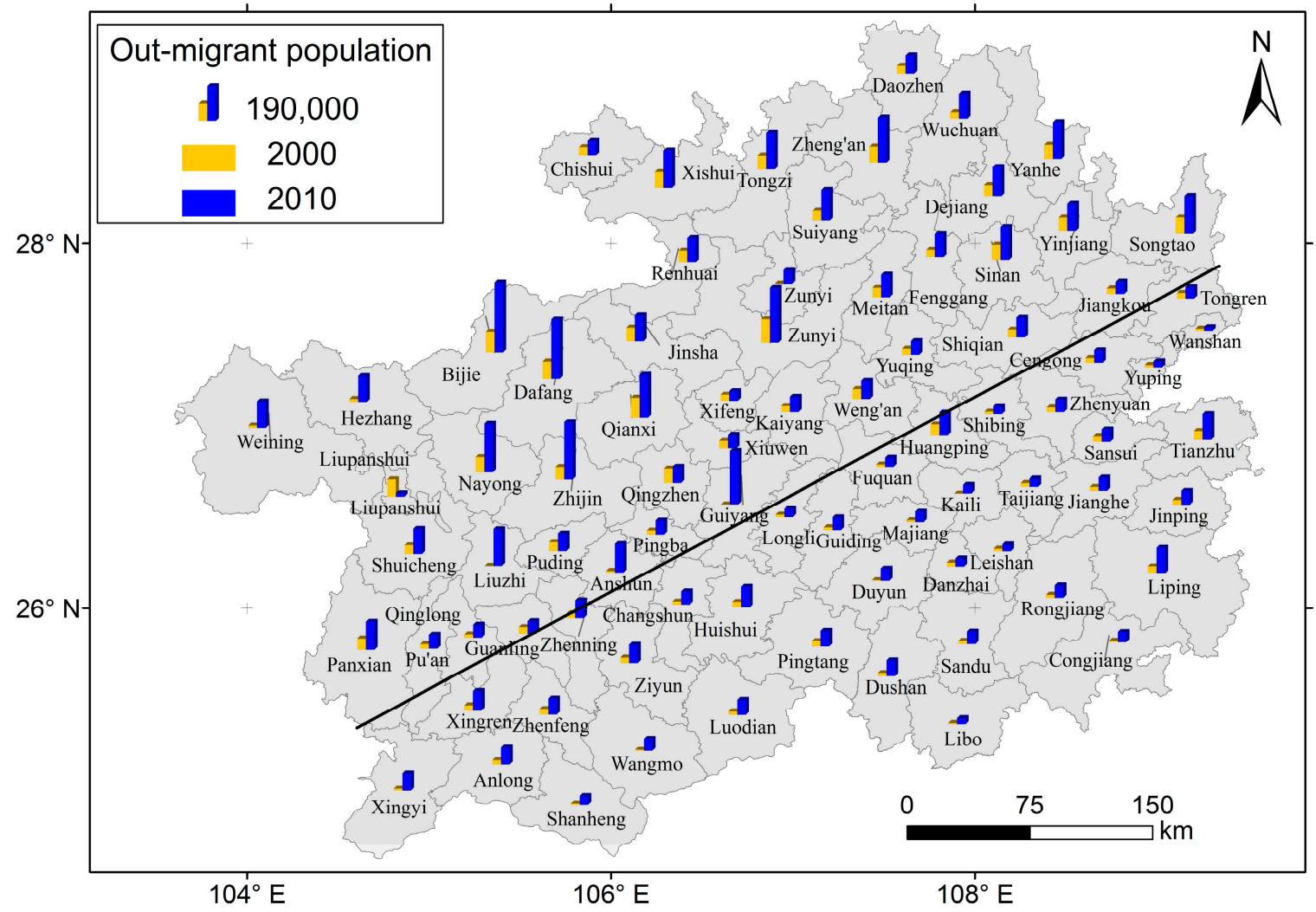

Figure 7. $(\mathbf{a}, \mathbf{b})$ Trends in forest NDVI (\%) in different OMP groups. The black vertical lines intersecting the bars represent the standard deviation in each group.
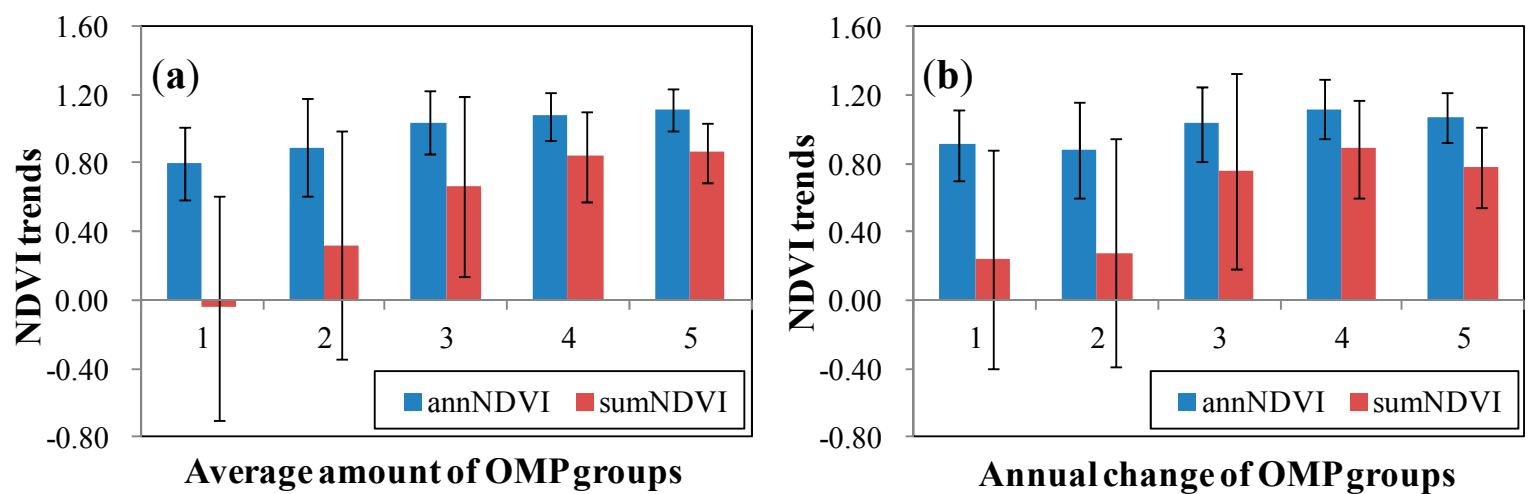

\subsection{The Implications of the Ecological Afforestation Project and Out-Migration on Forest Restoration}

Afforestation is conducive to forest restoration, and it involves more than simply increasing the forest area. The afforestation of marginal land can change the configuration of the forest landscape and increase the soil water capacity, which has benefits for forest growth, especially for forest in a karst area. In Guizhou Province, a large amount of afforestation of cropland and grassland has occurred in the core forest area (Figure 8), and this conversion will inevitably improve the continuity of the forest landscape. On the other hand, rural households rely heavily on biomass fuels to meet their energy needs, and firewood is a major biomass fuel [40]. Through the implementation of the ecological afforestation project, rural household income has increased due to subsidies from the central 
government, and this rise could lead to a switch from firewood to cleaner and more efficient fuels $[41,42]$. This may also reduce the negative impact on forest and contribute to forest restoration in this region.

Migration changes the size and structure of the original population and also influences regional land use and vegetation changes $[43,44]$. Large numbers of members of the working age population have moved out of Guizhou Province, which has helped to promote forest restoration for several reasons [45]. First, the increased income may reduce the heavy dependency of migrant households on land [19] and promote the abandonment of sloping cultivated land. According to an investigation of rural households in Guizhou karst area, the income of migrant household was higher than that of households with no or less out-migration [46], and the dependency on traditional crop and livestock farming was much lower [47]. Additionally, negative disturbances, such as gathering firewood, may be reduced as male laborers move out of the area. Because gathering firewood is a time-consuming and labor-intensive process, it is more commonly undertaken by male residents [48]. The amount of male laborers in Guizhou Province has decreased by about $17 \times 10^{4}$ during the past decade, which may have reduced the availability of labor for gathering firewood. More importantly, the increased income from out-migration could promote a switch from firewood to cleaner and more efficient fuels, as mentioned above. Other factors related to out-migration, such as livelihood diversification and more sustainable farming techniques, may also contribute to forest restoration.

Figure 8. Conversions of cropland and grassland to forest in different forest margins

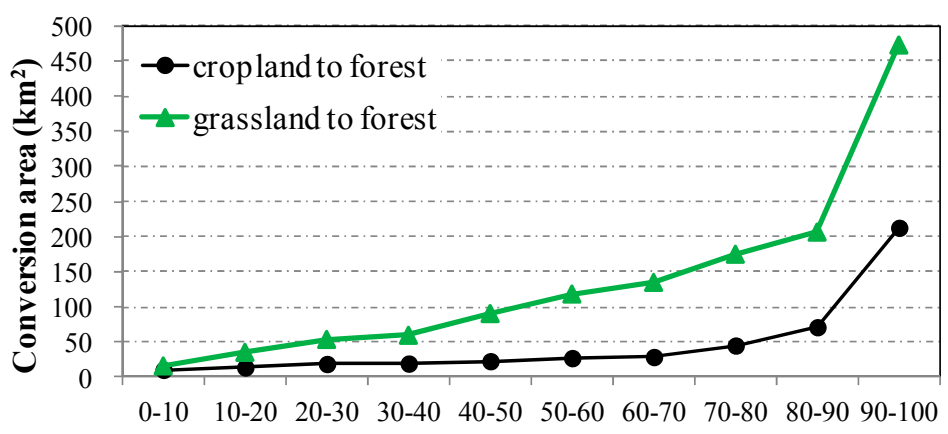

Forest margins

Possible uncertainties come from data. Land use data used in this study was interpreted from Landsat TM/ETM+ and HJ-1 CCD images, and then distribution of forest and the transformation between forest and other land use were extracted and converted to $1 \times 1 \mathrm{~km}$. However, NDVI data was from MODIS sensor. Although these two data were reprojected to the same spatial reference, the perfect consistency is difficult to guarantee and this problem is also not avoidable in the combination analysis of data from different sources. Another uncertainty related with data is from OMP data. Due to the lack of OMP records, the amount of OMP was estimated, based on total amount of immigration and net migration. The amount of OMP may be underestimated due to extras deduction of the amount of inhabitants without household registers; even so, the spatial patterns of OMP would not be influenced. 


\section{Conclusions}

This study investigated the influence of climate change and human-induced factors (an ecological afforestation project and out-migration) on recent greening trends in Guizhou Province, which includes the largest karst area in China.

From 2000 to 2010, general greening trends in forest areas have been observed, and these strong trends have mainly occurred in the karst area. These greening trends cannot be explained by a single factor such as climate, although the warming climate coupled with the decrease in precipitation does explain some of the changes. Major changes can be attributed to human-induced factors, especially in the karst areas. Due to the implementation of an ecological afforestation project, a proportion of cropland and grassland has been transformed to forest, and this conversion partly contributed to forest restoration from 2000 to 2010. Additionally, out-migration has also contributed. Large numbers of people, including many of working age, have moved out of the region, which has promoted forest restoration by reducing negative disturbance of forest areas and promoting abandonment of sloping cultivated land.

Our study only focused on identifying the major factors (i.e., climate change or human-induced factors) that were responsible for general forest restoration. Based on the regression analysis from climate sites, the contribution of climate change to forest variation was identified. Employment of more detailed climate data will help to explore the spatial variation of the contribution. In addition, according to our results, forest restoration can be primarily attributed to human factors. Discrimination of human- induced forest restoration is needed more efforts in the further. And what's more, employment of detailed household survey data specifically tailored to the out-migration-environment relationship will also help to deepen the understanding of the mechanisms.

\section{Acknowledgments}

This research was supported by the National Science \& Technology Pillar Program during the "12th Five-Year" Plan Period (Grant No. 2012BAI32B07 and 2012BAI32B06) and the National Natural Science Foundation (Grant No. 41301155). We also thank the Journal Editor and the anonymous reviewers for their useful comments and great efforts on this paper.

\section{Author Contributions}

Hongyan Cai and Xiaohuan Yang designed this study, and Hongyan Cai was responsible for the paper writing. Kejing Wang and Linlin Xiao were mainly responsible for the data collection and processing. All the authors were involved in data analysis, as well as the discussion of the results.

\section{Conflicts of Interest}

The authors declare no conflict of interest. 


\section{References and Notes}

1. Li, Y.; Shao, J.; Wang, S.; Wei, C. A conceptual analysis of Karst ecosystem fragility. Prog. geogr. 2006, 25, 1-9. (In Chinese)

2. White, M.A.; Running, S.W.; Thornton, P.E. The impact of growing-season length variability on carbon assimilation and evapotranspiration over 88 years in the eastern US deciduous forest. Int. J. Biometeorol. 1999, 42, 139-145.

3. Lunetta, R.S.; Knight, J.F.; Ediriwickrema, J.; Lyon, J.G.; Worthy, L.D. Land-cover change detection using multi-temporal MODIS NDVI data. Remote Sens. Environ. 2006, 105, 142-154.

4. Tüshaus, J.; Dubovyk, O.; Khamzina, A.; Menz, G. Comparison of Medium Spatial Resolution ENVISAT-MERIS and Terra-MODIS time series for vegetation decline analysis: A case study in Central Asia. Reomte Sens. 2014, 6, 5238-5256.

5. Zhu, L.K.; Southworth, J. Disentangling the relationships between net primary production and precipitation in Southern Africa Savannas using satellite observations from 1982 to 2010. Remote Sens. 2013, 5, 3803-3825.

6. Fisher, J.I.; Mustard, J.F.; Vadeboncoeur, M.A. Green leaf phenology at Landsat resolution: Scaling from the field to the satellite. Remote Sens. Environ. 2006, 100, 265-279.

7. Yu, F.F.; Price, K.P.; Ellis, J.; Shi, P.J. Response of seasonal vegetation development to climatic variations in eastern central Asia. Remote Sens. Environ. 2003, 87, 42-54.

8. de Jong, R.; Verbesselt, J.; Schaepman, M.E.; de Bruin, S. Trend changes in global greening and browning: Contribution of short-term trends to longer-term change. Glob. Change Biol. 2012, $18,642-655$.

9. Lucht, W.; Prentice, I.C.; Myneni, R.B.; Sitch, S.; Friedlingstein, P.; Cramer, W.; Bousquet, P.; Buermann, W.; Smith, B. Climatic control of the high-latitude vegetation greening trend and Pinatubo effect. Science 2002, 296, 1687-1689.

10. Wang, X.H.; Piao, S.L.; Ciais, P.; Li, J.S.; Friedlingstein, P.; Koven, C.; Chen, A.P. Spring temperature change and its implication in the change of vegetation growth in North America from 1982 to 2006. Proc. Natl. Acad. Sci. 2011, 108, 1240-1245.

11. Zhou, L.; Kaufmann, R.K.; Tian, Y.; Myneni, R.B.; Tucker, C.J. Relation between interannual variations in satellite measures of northern forest greenness and climate between 1982 and 1999. J. Geophys. Res.-Atmos. 2003, 108, doi:10.1029/2002jd002510.

12. Suzuki, R.; Tanaka, S.; Yasunari, T. Relationships between meridional profiles of satellite-derived vegetation index (NDVI) and climate over Siberia. Int. J. Climatol. 2000, 20, 955-967.

13. Zhou, L.M.; Tucker, C.J.; Kaufmann, R.K.; Slayback, D.; Shabanov, N.V.; Myneni, R.B. Variations in northern vegetation activity inferred from satellite data of vegetation index during 1981 to 1999. J. Geophys. Res.-Atmos. 2001, 106, 20069-20083.

14. Krishnaswamy, J.; John, R.; Joseph, S. Consistent response of vegetation dynamics to recent climate change in tropical mountain regions. Glob. Change Biol. 2014, 20, 203-215.

15. de Beurs, K.M.; Wright, C.K.; Henebry, G.M. Dual scale trend analysis for evaluating climatic and anthropogenic effects on the vegetated land surface in Russia and Kazakhstan. Environ. Res. Lett. 2009, 4, doi:10.1088/1748-9326/4/4/045012. 
16. Xiao, J.F.; Moody, A. Trends in vegetation activity and their climatic correlates: China 1982 to 1998. Int J. Remote Sens. 2004, 25, 5669-5689.

17. Zhao, Y.X.; Wang, C.Y.; Wang, S.L.; Tibig, L. Impacts of present and future climate variability on agriculture and forestry in the humid and sub-humid tropics. Climatic Change 2005, 70, 73-116.

18. Su, W.; Yang, H.; Li, Q.; Guo, Y.; Chen, Z. Rock land desertification and its controlling measurements in the karst mountainous region, Southwest of China. Chin. J. Soil Sci. 2006, 37, 447-451. (In Chinese)

19. Van der Geest, K.; Vrieling, A.; Dietz, T. Migration and environment in Ghana: A cross-district analysis of human mobility and vegetation dynamics. Environ. Urban. 2010, 22, 107-123.

20. Xu, G.; Zhang, H.; Chen, B.; Zhang, H.; Innes, J.L.; Wang, G.; Yan, J.; Zheng, Y.; Zhu, Z.; Myneni, R.B. Changes in vegetation growth dynamics and relations with climate over China's Landmass from 1982 to 2011. Remote Sens. 2014, 6, 3263-3283.

21. Guo, X.; Zhang, F.; Liu, H.; Chen, X.; Huang, K. Karst exploration in Slovenia. Yunnan Geogr. Envrion. Res. 1997, 9, 1-6. (In Chinese)

22. Janos, M.; Klaudia, K.; Maria, S.; Andrea, K.B.; Andras, K.; Laszlo, M.; Monika, K.; Veronika, I. Hazards and landscape changes (degradations) on Hungarian karst mountains due to natural and human effects. J. Mt. Sci. 2013, 10, 16-28.

23. Parise, M.; Pascali, V. Surface and subsurface environmental degradation in the karst of Apulia (southern Italy). Environ. Geol. 2003, 44, 247-256.

24. Parise, M.; Qiriazi, P.; Sala, S. Evaporite karst of Albania: main features and cases of environmental degradation. Environ. Geol. 2008, 53, 967-974.

25. Li, Y. Rocky desertification of the land in Guizhou Province and analysis on economics of the three problems concerning agriculture. Green Econ. 2006, 24, 57-59. (In Chinese)

26. Chen, Q.; Xiong, K.; Lan, A. Analysis on karst rocky desertification in Guizhou based on "3S". Carsologica Sin. 2007, 26, 37-42. (In Chinese)

27. Huete, A.; Didan, K.; Miura, T.; Rodriguez, E.P.; Gao, X.; Ferreira, L.G. Overview of the radiometric and biophysical performance of the MODIS vegetation indices. Remote Sens. Environ. 2002, 83, 195-213.

28. Liu, J.Y.; Kuang, W.H.; Zhang, Z.X.; Xu, X.L.; Qin, Y.W.; Ning, J.; Zhou, W.C.; Zhang, S.W.; Li, R.D.; Yan, C.Z.; et al. Spatiotemporal characteristics, patterns, and causes of land-use changes in China since the late 1980s. J. Geogr. Sci. 2014, 24, 195-210.

29. Liu, J.Y.; Liu, M.L.; Tian, H.Q.; Zhuang, D.F.; Zhang, Z.X.; Zhang, W.; Tang, X.M.; Deng, X.Z. Spatial and temporal patterns of China's cropland during 1990-2000: An analysis based on Landsat TM data. Remote Sens. Environ. 2005, 98, 442-456.

30. Deng, X.Z.; Huang, J.K.; Rozelle, S.; Uchida, E. Cultivated land conversion and potential agricultural productivity in China. Land Use Policy 2006, 23, 372-384.

31. Liu, S.H.; Hu, Z.; Deng, Y.; Wang, Y.J. The regional types of China's floating population: Identification methods and spatial patterns. J. Geogr. Sci. 2011, 21, 35-48.

32. Piao, S.L.; Fang, J.Y.; Zhou, L.M.; Ciais, P.; Zhu, B. Variations in satellite-derived phenology in China's temperate vegetation. Glob. Change Biol. 2006, 12, 672-685.

33. Herrmann, S.M.; Anyamba, A.; Tucker, C.J. Recent trends in vegetation dynamics in the African Sahel and their relationship to climate. Glob. Environ. Chang. 2005, 15, 394-404. 
34. Evans, J.; Geerken, R. Discrimination between climate and human-induced dryland degradation. J. Arid Environ. 2004, 57, 535-554.

35. Piao, S.L.; Fang, J.Y.; Zhou, L.M.; Guo, Q.H.; Henderson, M.; Ji, W.; Li, Y.; Tao, S. Interannual variations of monthly and seasonal normalized difference vegetation index (NDVI) in China from 1982 to 1999. J. Geophys. Res.-Atmos. 2003, 108, doi:10.1029/2002JD002848.

36. Wang, J.; Rich, P.M.; Price, K.P. Temporal responses of NDVI to precipitation and temperature in the central Great Plains, USA. Int J. Remote Sens. 2003, 24, 2345-2364.

37. McGrew, J.C., Jr.; Monroe, C.B. An Introduction to Statistical Problem Solving in Geography; McGraw Hill: New York, NY, USA, 2000; p. 254.

38. Wang, B.; Yang, S. Change in vegetation cover in Guizhou karst regions based on NOAA/AVHRR. Carsologica Sin. 2006, 25, 157-162. (In Chinese)

39. Zheng, Y.; Niu, L.; Wu, R.; Wu, Z.; Luo, X.; Cai, Z. Vegetation cover change in Guizhou of Southwest China in 1982-2003 in response to climate. Chin. J. Ecol. 2009, 28, 1773-1778. (In Chinese)

40. Tang, L.; Liu, Z.; Xiong, K.; Xiao, H. Study on structure and effects of rural household energy in rocky desertification area-A case in salaxi of Guizhou. J. Guizhou Norm. Univ. (Nat. Sci.) 2013, 31, 96-102. (In Chinese)

41. Heltberg, R. Factors determining household fuel use in Guatemala. J. Environ. Dev. Econ. 2005, $10,2337-2361$.

42. Liang, Y.; Fan, J.; Sun, W.; Han, X.; Sheng, K.; Ma, H.; Xu, Y.; Wang, C. The influencing factors of rural household energy consumption structure in mountainous areas of Southwest China: A case study of Zhaotong city of Yunnan Province. Acta Geogr. Sin. 2012, 67, 221-229. (In Chinese)

43. Carr, D. Population and deforestation: Why rural migration matters. Prog. Hum. Geogr. 2009, 33, 355-378.

44. Olsson, L.; Eklundh, L.; Ardo, J. A recent greening of the Sahel—trends, patterns and potential causes. J. Arid Environ. 2005, 63, 556-566.

45. Rudel, T.K.; Coomes, O.T.; Moran, E.; Achard, F.; Angelsen, A.; Xu, J.C.; Lambin, E. Forest transitions: Towards a global understanding of land use change. Glob. Environ. Chang. 2005, 15, 23-31.

46. Xing, P.; Fan, S.; Luo, X.; Zhang, X. Inequality in western rural China: A household anaylsis in Guizhou Province. China Econ. Q. 2008, 8, 325-346. (In Chinese)

47. Yang, C.Y.; Lu, Q.; Xie, L.S. Rural-urban migration, rural household income and local geographical contexts-A case of northwestern Guangxi, China. Chin. Geogr. Sci. 2008, 18, 17-23.

48. Barbieri, A.F.; Carr, D.L. Gender-specific out-migration, deforestation and urbanization in the Ecuadorian Amazon. Glob. Planet. Change 2005, 47, 99-110.

(C) 2014 by the authors; licensee MDPI, Basel, Switzerland. This article is an open access article distributed under the terms and conditions of the Creative Commons Attribution license (http://creativecommons.org/licenses/by/4.0/). 